\title{
A situated analysis of instructions in paraclimbing training with visually impaired athletes
}

\section{Une analyse située des instructions au cours des entraînements de paraclimbing avec des athlètes malvoyants}

\author{
Monica Simone ${ }^{1 \text { a }}$ \\ ${ }^{1}$ Department of Philosophy and Communication Studies (FILCOM) \\ University of Bologna, Italy
}

\begin{abstract}
Indoor sport climbing performed by athletes with visual impairment is realized by trainer and climber working as a couple and is routinely based on instructions. It can be considered a perspicuous setting (Garfinkel, 2002) for investigating how sighted and visually impaired participants coordinate their perception and actions in the material environment while accomplishing mobile tasks. Drawing on previous ethnomethodological and CA studies on instructions in mobile activities, the analysis of an excerpt of a guided climbing session provides the ground for a detailed description of some features of instructions that are specific to this context. The analysis aims at showing that the trainer's instructions are not only timely adjusted to the course of action, but, importantly, that they also display the trainer's orientation to the climber's sensory impairment.
\end{abstract}

\begin{abstract}
Résumé. L'escalade pratiquée par les athlètes malvoyants est accomplie par le couple athlète-instructeur par le biais des instructions que ce dernier produit au fur et à mesure que l'escalade progresse. Cela peut ainsi être considéré comme un perspicuous setting (Garfinkel, 2002) pour étudier comment les participants, voyants et malvoyants, coordonnent leur perception et leurs actions pour accomplir des tâches mobiles dans l'environnement matériel. À partir des études en ethnométhodologie et en analyse de la conversation portant sur les instructions dans la réalisation d'activités mobiles, cette étude propose l'analyse d'un extrait d'une escalade guidée. L'analyse vise à montrer les caractéristiques des instructions spécifiques à ce contexte, y compris comment les instructions de l'entraîneur s'adaptent au mouvement en cours de l'athlète et comment elles traitent la déficience sensorielle du grimpeur.
\end{abstract}

\footnotetext{
${ }^{\text {a }}$ Corresponding author: monica.simone2@unibo.it
} 


\section{Introduction}

Climbing is an increasingly popular sport, which will be included among the Olympic disciplines with the 2020 Summer Olympics in Tokyo. In the last decade, the increasing availability of climbing gyms has made this sport more accessible for people with physical and intellectual disabilities. The International Federation of Sport Climbing has been hosting paraclimbing competitions since 2006 and sport climbing has been officially recognized by the Italian Paralympic Committee in 2011. Since the value of this sport for educational and rehabilitation purposes has been recognized, indoor climbing courses have been included in some Italian school programs, and some gyms have provided climbing training specifically designed for people with disabilities.

Indoor climbing consists in reaching the top of an artificial wall specifically designed for reproducing some features of natural rocks. Each climbing wall may include several routes consisting in sequences of holds of the same colour. Insofar as they are designed to be recognizable paths, climbing routes form material inscriptions (Garfinkel, 2002; Goodwin, 1997: 116; Ueno, 2000: 61) that provide visual information and instructions for planning and accomplishing the ascent. Indeed, the arrangement and orientation of the holds forming the route configure a sequence of possible climbing actions. According to their size, shape and location, holds provide opportunities and constraints for the climber's movement, and can be used as handholds or footholds, depending on the climber's current position along the route.

In order to allow the participation of visually impaired athletes, indoor climbing is adapted by including a sighted participant (usually a trainer) in the role of guide. While performing the climb, blind and partially sighted athletes are verbally guided by their trainers, both in training and in competitions, particularly in the Lead game ${ }^{I}$. Although being an individual sport, climbing performed by athletes with visual impairment is quite similar to a team sport, since it is realized by the trainer-climber couple and is routinely based on instructions. The ability to climb a route as a couple in which one participant (the trainer) verbally instructs the other participant (the climber) implies an accurate interpersonal coordination. Moreover, the asymmetrical distribution of sensory resources (visual for the trainer, haptic for the climber) for accessing the spatial configuration of the climbing route poses the practical problem of establishing and sharing a spatial reference system that is suitable for both participants, as well as adjusted to the changing spatial contingencies due to mobility. For all these reasons, climbing can be considered a perspicuous setting (Garfinkel, 2002) for investigating how sighted and visually impaired participants coordinate their perception and actions in the material environment while accomplishing mobile tasks.

Drawing on the theoretical and methodological framework of Ethnomethodology and Conversation Analysis, the paper proposes a situated study of instructions in the context of climbing training. The analysis of an excerpt taken from a guided climbing session provides the ground for a detailed description of some features of instructions that are specific to this context. The paper aims at showing that the instructions display the trainer's orientation to the climber's sensory impairment, in addition to being timely adjusted to the course of action and to the contingencies due to mobility.

\footnotetext{
${ }^{1}$ In the Lead game competitors have to climb on an increasingly difficult route trying to reach the top. The performance ranking is established on the basis of the level of difficulty associated to the highest hold reached by the climber. Noticeably, Lead game competitions are performed on routes that climbers have never experienced before.
} 


\section{Data and Method}

The study is based on a corpus of video recorded paraclimbing training, for a total of about 12 hours. Data were collected in 2016, during a three-month ethnographic work in two different gyms in Bologna (Italy). Participants are two sighted trainers (members of the Italian Federation of Sport Climbing, F.A.S.I.) and three élite climbers with visual impairments (one blind climber and two partially sighted ones) who are members of a paraclimbing team. Data were collected after obtaining the participants' written consent according to the Italian law n. 196/2003 "Codice in materia di protezione dei dati personali", concerning the treatment of personal and sensitive data. Data collection also obtained formal approval by the Ethics Committee of the University of Bologna.

The corpus documents 53 guided climbs on different routes. Video recordings were realized by placing a camera behind the trainer, opposite to the climbing wall, in order to frame all the relevant details of the route layout. Verbal instructions provided by the trainer were recorded using a radio-microphone connected to the camera.

For the purposes of the present article, I refer to a sub-corpus of 9 climbs performed on routes that trainer and climber were trying together for the first time. I chose to restrict the analysis to such cases in order to exclude phenomena related to the memorization of the routes, which can occur as a result of repeated practice. Moreover, climbing on new routes is the same condition that athletes and their trainers face when participating in Lead game competitions (see note 1).

Data are transcribed according to the conventions elaborated by Jefferson for talk (Jefferson, 2004) and developed by Mondada for embodied conduct (Mondada, 2016). The transcripts are accompanied by screenshots showing the multimodal aspects being analysed.

\subsection{Background: instructions and mobile activities}

The present study draws on the body of research concerning instructions in social interaction developed in Ethnomethodology and Conversation Analysis. In Conversation Analysis, the term instructions refer to certain social actions whose main characteristic is that of being "designed to get someone to do something", as in the definition of directives by Goodwin (2006: 517). As pointed out by the ethnomethodological and conversation analytic literature, regardless of the setting, instructions do not unilaterally determine the corresponding course of actions, rather their projected outcome is fully realized by the following actions (Amerine \& Bilmes, 1988), that is, by the instructed actions (Garfinkel, 2002), and is tied to the local contextual configurations (Goodwin, 2000) and to the sequential environment of the activity. Such indexicality and indeterminacy of instructions means that their efficiency crucially relies on their situated interpretation by the participants. In this respect, it should be noted that various kinds of resources, among which speech, embodied actions and other multimodal resources, can constitute - or better, can be situatedly interpreted as - instructions. Moreover, instructions have been analysed also considering their orientation to the recipient's ability to comply with them (Curl \& Drew, 2010; Deppermann, 2015).

Most authors describe instructions and instructed actions as components of an adjacency pair, in which the instruction occurring as the first pair-part projects the instructed action as the complying second pair-part. Instructions-in-interaction have been studied mostly in the context of learning, but they occur in a variety of activities requiring the coordination among participants (for reviews, see Lindwall, Lymer \& Greiffenhagen, 2015; Mondada, 2013 and 2014). The present study draws particularly on a recent line of research dealing with instructions in the context of mobile activities carried out both in real environment, such as in driving lessons (Deppermann, 2015; De Stefani \& Gazin, 2014) and car 
conversations (Haddington, 2013), and in virtual environment, like in video-games (Mondada, 2013).

\subsection{The Situated Activity System of guided climbing}

Studying the organization of instructions-in-interaction requires considering the entire praxeological context of the activity, including humans and artifacts. The Situated Activity System (Goffman, 1961; Goodwin, 1997) of guided climbing includes a sighted trainer, a visually impaired climber and the material resources of climbing routes.

During the guided climbing sessions, the trainer stands on the ground, opposite to the wall, in a relatively static position, while the climber moves upwards on the route. The trainer's and climber's reciprocal positioning displays a face-to-back orientation, configuring a spatial arrangement that lets the trainer monitor the climber's movements. The trainer instructs the climber by means of a microphone, guiding him/her while climbing on a selected route. The trainer's instructions are verbal, whereas the climber's actions consist of body movements performed mostly in a tacit way.

The ascent on the route is organized stepwise as a series of moves, which consist in reaching a foothold and a handhold one after the other. Normally, in accomplishing a move, climbers proceed symmetrically (right foot $\rightarrow$ right hand). These aspects are part of a shared knowledge between trainer and climber.

\section{Instructions and instructed actions in guided climbing}

In guided climbing, the organization of the ascent as a series of moves consisting in reaching a foothold and a handhold at a time is reflexively tied to the sequential organization of instructions and instructed actions. Indeed, every move is opened by the trainer, who provides instructions concerning the position of the holds to be reached for proceeding in the climb, and is accomplished by the climber, who moves consistently with the instructions just received. Such sequence is frequently expanded with the insertion of further instructions. This routinely happens in guided climbs performed on new routes. In these cases, while the climber is moving in the previously instructed direction, the trainer provides further instructions, which refer to the current movement.

The excerpt below offers the opportunity to analyse the details of the sequential positioning of instructions and the trainer's orientation and attention to the climber's visual impairment. At the beginning of the excerpt, the climber (CLIMB) is making a stop after the accomplishment of the previous move (see Fig. 1). Then, the trainer (TRA) opens a new instructional sequence. The trainer's opening turn (1. 1-3) configures a set of instructions concerning an entire move, which consists in reaching a foothold (indicated by the red arrow in Fig. 1) and, subsequently, a handhold (indicated by the yellow arrow in Fig. 1). 

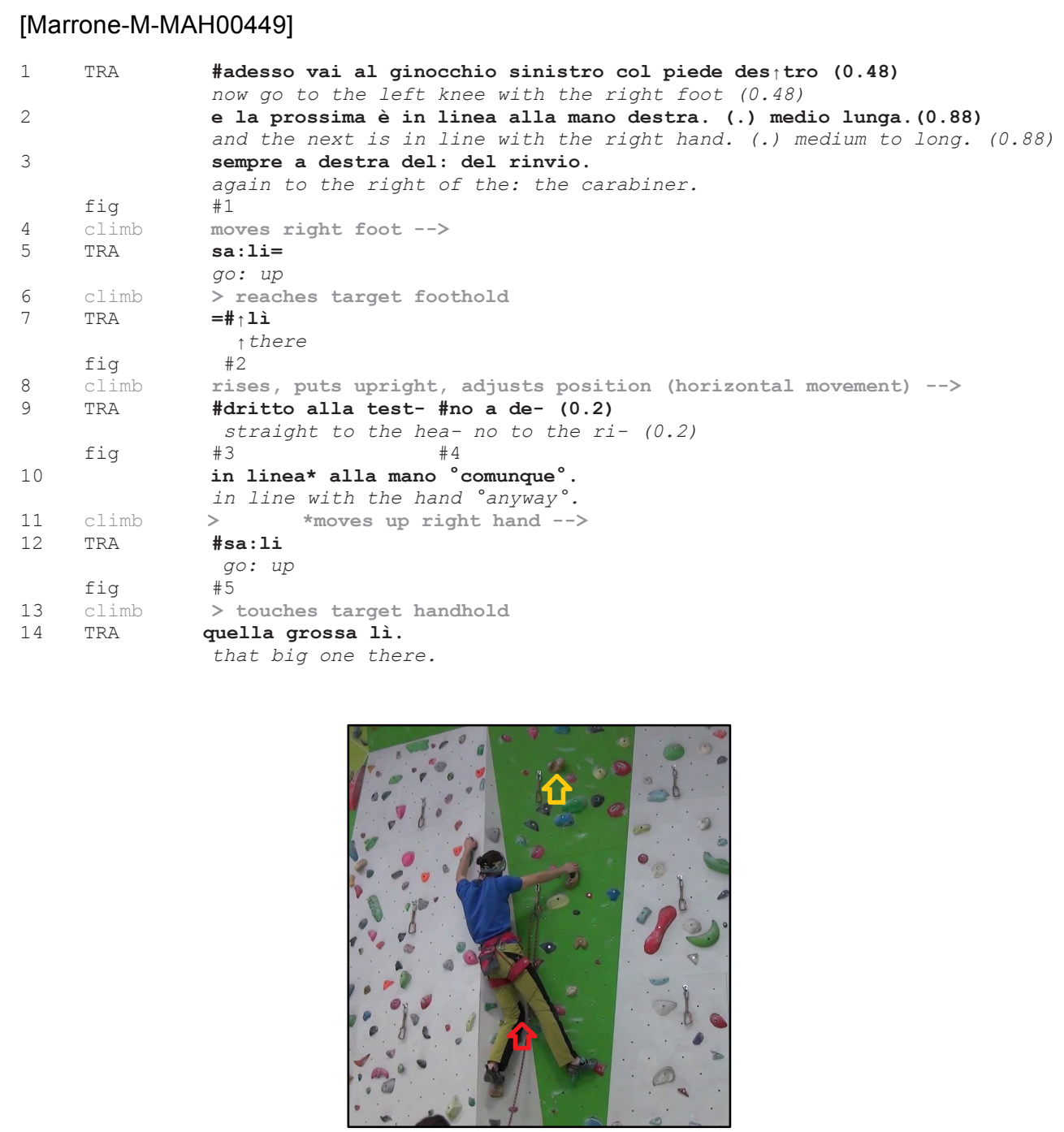

Figure 1. Position of the climber during the trainer's opening turn.

The first instruction at line 1 is delivered in the form of a directive, opened by the word "adesso/now", which marks the beginning of a new sequence. The directive contains a verb of motion ("vai/go"), its spatial complement ("al ginocchio sinistro/to the left knee") and a prepositional adjunct indicating which limb the climber must move ("col piede destro/with the right foot"). By saying "al ginocchio sinistro/to the left knee", the trainer maps the position of the target foothold onto the position of a part of the climber's body (the left knee). By assuming the climber's knee as the ground for the spatial reference, she enables the climber to localize the foothold by using his proprioception.

Although being formatted as a syntactically and semantically complete directive, the instruction at line 1 does not obtain as a response the immediate execution of the action. Indeed, the climber remains in the same position while pulling slightly the holds he is grasping with the right and the left hand, as for testing their use in view of the next upward movement. In so doing, he displays that he interpreted the instruction just received for the foot movement as being part of a wider instructional turn which is to be continued. Possibly, it is due to the rising intonation on "des $\uparrow$ tro", which seems to project an extension 
of the trainer's turn-at-talk. The trainer, for her part, does not solicit a response by the climber. Rather, after a pause, she extends her turn by saying "e la prossima è/and the next is" (1. 2), where the adjective "prossima/next" is used as a noun (it is preceded by the definite article "la/the") and stands for "la prossima [presa]/the next [handhold]". Then, the trainer describes the position of the next handhold, by saying "in linea alla mano destra/in line with the right hand" (1.2), which means that the handhold is on the same line as the hold the climber is currently grasping with his right hand. Here again, the trainer assumes the climber's body (i.e., his right hand) as the ground for the spatial reference. Soon after, by saying "medio lunga/medium to long" (1. 2), the trainer provides information about the distance of the handhold. Finally, after another pause, by saying "sempre a destra del: del rinvio/again to the right of the: the carabiner" (1. 3), she describes the position of the handhold in relation to that of the carabiner, whose location is already known to the climber ${ }^{2}$.

Looking at the entire trainer's turn it should be noted that if the first utterance at line 1 configures an instruction whose projected outcome is made explicit, the interpretation of the following part of the trainer's turn - namely, the description at lines 2-3 - as an instruction requiring a corresponding course of action builds upon the climber's skilled interpretation of what the entire trainer's turn is about, that is, it builds upon the climber's knowledge of the internal structure of a move, which consists in reaching a foothold and a handhold one after the other.

The climber starts moving after the trainer's opening instructions are completed. He first moves his right foot (1.4) attempting to reach the foothold located near his left knee, as required in the first instruction (1. 1). While the climber is approaching the target hold, the trainer utters a directive, "sa:li/go: up" (1. 5), requiring the climber to proceed in the ongoing movement, as he actually does. Soon after, the deictic locative "lì/there" (1.7) is pronounced with a higher pitch than the preceding part of the trainer's turn. It occurs simultaneously with the achievement of the foothold and refers to the precise here-and-now of the climber's foot position, which is right on top of the foothold. Consequently, "lì/there" is not the spatial complement of the preceding verb, but rather it configures a distinct action: that of signalling that the target foothold has been reached (Fig. 2) and the instructed action is completed.

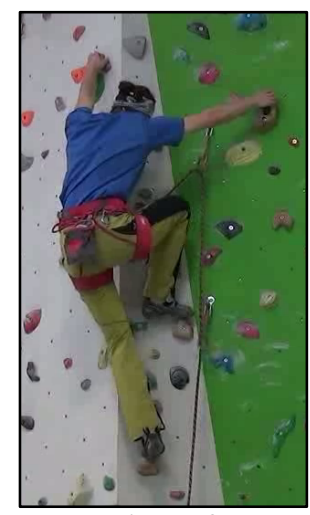

Figure 2

\footnotetext{
${ }^{2}$ Indeed, the trainer refers to the carabiner by using a definite noun. The climber knows where the carabiner is because he secured the safety rope at carabiners throughout the previous part of the ascent and because carabiners are placed at equal distance (see Fig. 1).
} 
Once reached the foothold, thereby complying with the first instruction, the climber rises on the right foot until putting himself upright (1.8) and then he adjusts his position, attempting to re-balance his centre of gravity, moving his upper body horizontally. In doing so, he visibly orients to the accomplishment of the second part of the move, which consists in reaching the handhold. At this point, the trainer intervenes (1. 9) providing further directions that refer to the location of the handhold (the same of the spatial description at lines 2-3) but are adjusted to the current position of the climber's body. When the climber's head is almost aligned with the handhold (Fig. 3), the trainer starts uttering "dritto alla test[a]-/straight to the hea[d]-" (1. 9). Soon after, she breaks off and then produces a first self-repair (1. 9: "no a de[stra]-/no to the ri[ght]-"), in an attempt to adjust the ongoing directions to the lateral movement of the climber's head (Fig. 4). This further utterance too is left incomplete and the trainer produces a second self-repair (1. 10: "in linea alla mano comunque/in line with the hand anyway"), thus recalling the description used at line 2 ("in linea alla mano destra/in line with the right hand"). In the meanwhile, the climber starts moving up his right hand (1.11) toward the handhold, before the completion of the trainer's turn.

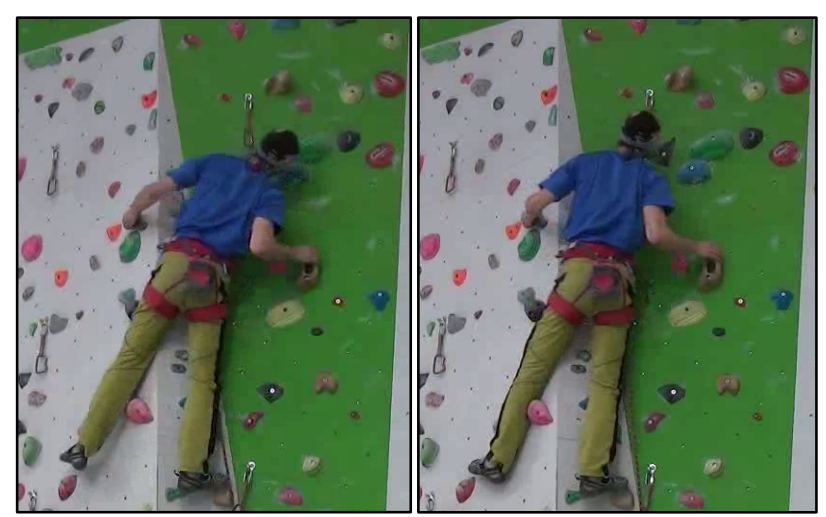

Figures 3-4

When the climber's hand is close to the handhold, the trainer utters a further instruction in the form of directive (1. 12, "sa:li/go: up"). Here, the trainer's intervention follows the climber's touch of a hold placed near the target handhold (Fig. 5). As already observed for the instruction at line 5, with the directive "sa:li/go: up" the trainer requires the climber to proceed moving until reaching the target.

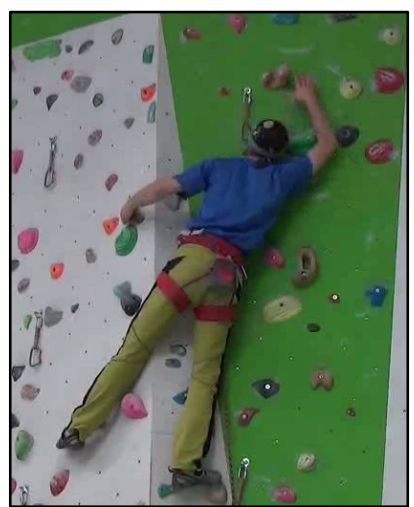

Figure 3 
Soon after, when the climber's right hand encounters the target handhold (1.13), the trainer says "quella grossa lì/that big one there" (1. 14). As previously observed at line 7 ("lì/there"), the trainer's turn is simultaneous with the climber's achievement of the target hold and signals that the instructed action has come to an end. In both cases (1. 7, "lì/there"; 1. 14, "quella grossa lì/that big one there"), the trainer's verbal acknowledgment seems to function as a means for sharing the completion of the trajectory of action carried out cooperatively. This function of the trainer's closing turn is reinforced by making reference to a physical characteristic of the handhold (its size), which can be accessed both visually and by means of touch.

\section{Discussion}

The excerpt showed the interactional work carried on by trainer and climber for accomplishing a move which consists in reaching a foothold and a handhold one after the other. The organization of such work reveals that the trainer's instructions have distinct functions depending on their sequential positioning with respect to the climber's movement.

The instructions delivered by the trainer at the beginning of the excerpt (1.1-3) have the function of locating the foothold and the handhold, thus compensating the lack of visual spatial information needed to the athlete to orient in the climbing space. Central to such instructions is the way spatial information is formatted for being accessible to the blind climber: the trainer uses spatial descriptions which are grounded in the climber's body (1. 1: "al ginocchio sinistro/to the left knee"; 1. 2: "in linea alla mano destra/in line with the right hand") or refer to objects whose location is known to the recipient (1. 3: "a destra del rinvio/to the right of the carabiner", see also note 2).

Various kinds of verbal utterances (the directive at line 1 and the space descriptions at lines 2-3) are situatedly treated by the climber as instructions. The indexicality and indeterminacy of the trainer's instructions, which do not specify every aspect of the corresponding actions, builds upon the skilled interpretation of the climber, who autonomously accomplish the projected outcome by means of a series of body movements. This is particularly evident at lines 8 and 11, where the climber prepares and subsequently does the right-hand movement needed to reach the target handhold by using the spatial information provided by the trainer at lines 2-3.

During the climber's movement, the trainer can make relevant changes in the spatial relations between the moving body and the target hold, especially when the body part that is moving is the same taken as the ground for the spatial description previously provided. This is particularly evident at lines 9 ("dritto alla test[a]- no a de[stra]-/straight to the hea[d]- no to the ri[ght]) and 10 ("in linea alla mano comunque"/in line with the hand anyway"), where the trainer's turn reflexively adjusts to the contingencies of the climber's movement, displaying the trainer's finely tuned analysis of the movement trajectory. Instructions occurring while the climber's movement is underway (1. 5, 9-10 and 12) do not project further instructed actions but refer to the climber's ongoing movement. The aim of such instructions seems to be that of supporting the climber in successfully completing his action, as shown at lines 5 and 12 ("sa:li/go: up").

In both cases - instructions opening the sequence and instructions referring to current movements - the focus is on the spatial aspects of the climber's bodily actions rather than on the temporal constraints of the performance, which are central in other kinds of mobile activities and sports requiring the accomplishment of bodily actions in a timely manner. However, given that the participants' sensory access to the environment is asymmetrical, the sequential organization of the trainer's instructions with respect to the climber's movement is central to the participants' coordination, because it contributes to locally 
establish and maintain the mutuality between what is within the trainer's visual access and what falls under the climber's touch and proprioception. Indeed, the trainer uses time as a resource for grounding spatial information in specific moments of the climber's movements, as suggested also by the analysis of the verbal acknowledgments uttered simultaneously with the climber's achievement of the target hold, such as "lì/there" (1. 7) and "quella grossa lì/that big one there" (1. 14). In these cases, the deictic locatives and demonstratives, which refer to the climber's touch in a timely manner, display the trainer's 'attunement' to the climber's bodily experience of the material environment.

\section{Appendix: transcription conventions}

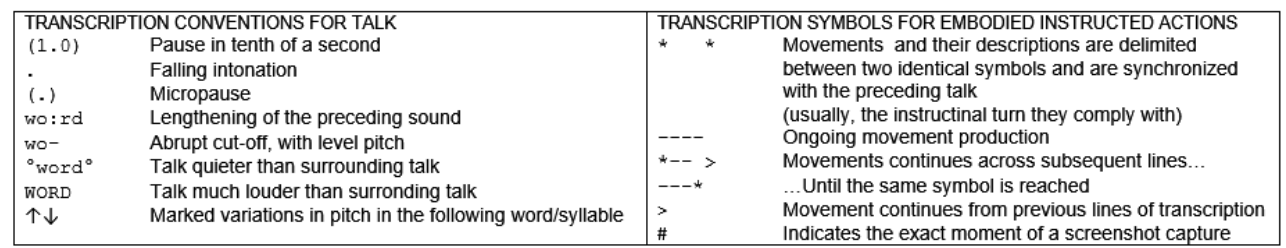

\section{Bibliography}

Amerine R. \& Bilmes J. (1988). Following instructions. Human Studies, Vol. 11, No. 2-3, p. 327-339.

Craven A. \& Potter J. (2010). Directives: entitlement and contingency in action. Discourse Studies, Vol. 12, No. 4, p. 419-442.

De Stefani E. \& Gazin A.-D. (2014). Instructional sequences in driving lessons: mobile participants and the temporal and sequential organization of actions. Journal of Pragmatics Vol. 65, p. 63-79.

Garfinkel H. (2002). Ethnomethodology's Program, Oxford: Rowman \& Littlefield.

Goffman E. (1961). Encounters: Two Studies in the Sociology of Interaction. Indianapolis: Bobbs-Merrill Company, Inc.

Goodwin C. (1997). The blackness of black: color categories as situated practice. In L. B. Resnick, R. Säljö, C. Pontecorvo \& B. Burge (Eds.), Discourse, Tools, and Reasoning: Essays on Situated Cognition. Berlin/Heidelberg/New York: Springer, p. 111-140.

Goodwin C. (2000). Action and embodiment within situated human interaction. Journal of Pragmatics, Vol. 32, No. 10, p. 1489-1522.

Goodwin M. H. (2006). Participation, affect, and trajectory in family directive/response sequences. Text and Talk, Vol. 26, No. 4-5, p. 515-543.

Haddington P. (2013). Projecting mobility: passengers directing the driver at junctions. In P. Haddington, L. Mondada \& M. Nevile (Eds.), Interaction and Mobility: Language and the Body in Motion. Berlin/Boston: De Gruyter, p. 179-209.

Jefferson G. (2004). Glossary of transcript symbols with an introduction. In G. H. Lerner (Ed.), Conversation Analysis. Studies from the First Generation. Amsterdam/Philadelphia: John Benjamins, p. 13-31. 
Lindwall O., Lymer G. \& Greiffenhagen C. (2015). The sequential analysis of instruction. In N. Markee (Ed.), The Handbook of Classroom Discourse and Interaction. Hoboken, NJ: John Wiley \& Sons, p. 142-157.

Mondada L. (2013). Coordinating mobile actions in real time: the timely organization of directives in video games. In P. Haddington, L. Mondada \& M. Nevile (Eds.), Interaction and Mobility. Language and the Body in Motion. Berlin/Boston: De Gruyter, p. 300-341.

Mondada L. (2014). Instructions in the operating room: how the surgeon directs their assistant's hands. Discourse Studies, Vol. 16, No. 2, p. 131-161.

Mondada L. (2016). Conventions for multimodality (version 3.0.6, July 2016), https://franzoesistik.philhist.unibas.ch/fileadmin/user_upload/franzoesistik/mondada_multi modal_conventions.pdf.

Ueno N. (2000). Ecologies of inscription: technologies of making the social organization of work and the mass production of machine parts visible in collaborative activity. Mind, Culture, and Activity, Vol. 7, No. 1-2, p. 59-80. 